\title{
EDITORIAL
}

\section{UNDERGRADUATE MEDICAL EDUCATION IN BANGLADESH- URGENCY TO EXPLORE CURRENT SITUATION AND FUTURE DIRECTION}

\author{
MD ROBED AMIN ${ }^{1}$, QUAZI TARIKUL ISLAM ${ }^{2}$
}

Undergraduate medical education (Bachelor of Medicine and Bachelor of Surgery - MBBS) started in the land of Bangladesh in 1948 with the establishment of Dhaka Medical College in response to be partition of British India to accommodate students returning from Kolkata Medical Colleges and others remaining in the territory of India ${ }^{1}$. From 1948 till the independence of Bangladesh in 1971, eight government medical colleges were established in different years, though Sir Salimullah Medical College was offering short (MBBS) courses to LMF holders only. Soon after the independence in 1972 Sir Salimullah Medical College stopped courses for LMF and started enrolling fresh students like other 7 government medical colleges. The first non-government medical college was established in 1985. Then gradually new medical colleges kept on adding both in the government and non-government ${ }^{2}$.

Bangladesh is committed for improving quality of medical education along with modernization and revising as per need of the country (GOB 2012, GED $2012)^{2,3}$. However, there was questions of standardization and unhappiness with the quality and management of non-governmental medical education $(\text { GOB 2012) })^{2}$ The unplanned establishment of huge numbers of medical colleges both in public and private sectors with limited resources in unexpected limited time with gross shortage of qualified faculties ( basic sciences particular) creates a big hue and cry in the medical education of Bangladesh.

The non-clinical subjects and other supportive environment for effective knowledge and skill development (GED 2015, MOHFW 2015a, HRMU 2016) faces critical crisis with 111 total medical colleges of variable standard ${ }^{4,5,6}$. Professional regulatory bodies are found to have inadequate capacities to enforce standards or quality among the professionals they represent (GED 2015) ${ }^{4}$. The accreditation through national accreditation body, Quality, standardization issues remain major challenges (MOHFW 2015a) ${ }^{5}$. There is lack of highest level of regulatory council in medical education also.

Bangladesh J Medicine 2019; 30 : 51-52

DOI: https://doi.org/ 10.3329/bjmed.v30i2.41529
There is defective planning of the Curriculum (ignoring the importance of demographic, cultural and socioeconomic realities of the country and lack of expertise in key stakeholders); defective admission policy, Curriculum contents lacks update and relevance, ineffective instructional methods, inadequate clinical training, poor objective assessment system, poorly designed Internship training programme, lack of teaching staff and resources, huge and unplanned establishment of new medical colleges and lack of community-based training ${ }^{4,7}$.

The integrated competency based curriculum established in many developed and other developing like India, Srilanka, Nepal etc is now focusing new competency module on ethics, behavior science and constructed communication skill for all medical graduate and medical teachers are trained to cop up the new competency. To acquire the SDG , the medical education and service need to updated quickly as the SDG section 4 aims to give universal health and education coverage with quality education within year $2030^{8}$. The best practiced in existing curriculum should be accompanied by new development of competency based curriculum development for every country including Bangladesh. Although neighboring countries took steps for time oriented changes, there has been lack of initiative of such novel approach in Bangladesh. These changes in a country need prior processed evidence generated to formulate the ideas.

Current medical curriculum for MBBS need to be updated keeping understanding the gaps in teaching methods and formulating ideas to resolve the gaps. Here are few novel ideas which can be incorporated in undergraduate curriculum 2012

1. Regarding admission test: question set is weak comprising poor standard of questions. The students are getting chance officially despite poor quality in english resulting in difficulty for them in following lectures. To judge English proficiency, more number for English can be allocated in admission test. Alternatively, English course may 
be initiated before getting started classes. Foreign students should be evaluated by entry test before admission. There should be search the cause why English medium students are lagging behind with good English proficiency.Attitude, behavior of students should be assessed before entry

2. 11 steps of integrated teaching need to be implemented practically. Steps should be redefined whether it can be done horizontally, vertically or spirally. It was introduced unwisely in 2012 curriculum without knowing in-depth of it and analyzing the present situation. Current teaching staff is not sufficient enough to support integrated teaching. Modules can be developed in favor of integrated teaching. Step by step introduction of this important methods needs to establish.

Though Malaysia and western world are practicing the integrated teaching fully but our neighboring country India is struggling to implement it successfully. Moreover, support from government and policy maker is important.

3. Pathology and pharmacology need to be taught in phase II of curriculum as students now have a vacant state in ward experience without having any knowledge on these two important subjects for clinical correlation. In case of forensic medicine, the topics needed to know is injury and medico legal aspects of it and forensic pathology can be merged with pathology. The poisoning cases need to be addressed in clinical medicine and only the fatal cases need forensic pathology

4. There should not be carry on system after failure of $1^{\text {st }}$ professional exam. Reduction of number of in course assessment examination like term final should take into consideration. Supplementary examination should be taken in a fixed center. Merging of students of curriculum 2002 with curriculum 2012 needed to be thought of.

5. Faculty development course needs to be executed properly. Subject committee and Phase committee meeting need to carry out regularly.

6. Group discussion is encouraged to prepare a good lectures and microteaching. Little group discussions are also encouraged to help students to overcome difficult topic. Learning difficulty of students and teaching difficulty of teachers should be rectified.

7. Monitoring should be done by CME. To implement effective monitoring method in our country, digital visit can be introduced instead of field visit.

8. The number of students for bedside teaching or small group teaching should not exceed 15

9. A post graduate degree holder should get a registrar post to ensure quality teaching.

10. Bed side teaching and patient exposure is mandatory. OPD placement has to be compulsory.
Subject committee should supervise it. The main responsibility goes to the Principal of a medical college or academic Co-ordinator.

The medical education around globe is changing with updated methods which are important to create an efficient community oriented empathic altruistic physician. The paradigm of medical education is shifted from teacher's oriented knowledge based to integrated competency based education. Developed countries already adopted the changes of graduate curriculum into action while the developing countries are on the process of change ${ }^{7.8}$.

Therefore, on the basis of needs, it is demanding to accommodate the new knowledge in medical education curriculum to consider the primary health care in the community and involving in scientific research on our own health issues. It is now well-established that health care services cannot be improved unless the defective educational process of the medical education, which produces the physicians and other health personnel changes dramatically. Medical education is practical and dynamic discipline and those need constant review and research to become as well as to remain a useful tool to the society.

\section{Md Robed Amin', Quazi Tarikul Islam²}

${ }^{1}$ Associate Professor of Medicine, Dhaka Medical College, ${ }^{2}$ Professor of Medicine, Popular Medical College

\section{References:}

1. Bangladesh Health Watch (BHW). 2008. The State of Health in Bangladesh 2007: Health Workforce in Bangladesh, Who Constitutes the Healthcare System? Dhaka. James P. Grant School of Public Health, BRAC University

2. Government of Bangladesh (GOB). 2012. National Health Policy 2011. Dhaka

3. General Economics Division(GED). 2012. Perspective Plan of Bangladesh 2010-2021: Making Vision 2021 A Reality. Dhaka. GED, Planning Commission

4. General Economics Division (GED). 2015. Seventh Five Year Plan FY2016-FY2020: Accelerating Growth, Empowering Citizens. Dhaka. Planning Commission

5. Health Bulletin 2018 (draft) accessed from www.dghs. gov.bd

6. Human Resources Management Unit (HRMU). 2016. Bangladesh Health Workforce Strategy 2015. Dhaka. HRMU, MOHFW

7. MOHFW. 2015a. Health, Nutrition and Population Strategic Investment Plan (HNPSIP) July 2016-June 2021: Better Health for a Prosperous Society (Draft 2.1). Dhaka

8. World Health Organization (WHO). 2006. Working together for health. The World Health Report. Geneva. WHO 